\title{
PRESENÇAS DE MIGRANTES INTERNACIONAIS NA EDUCAÇÃO E NA ASSISTÊNCIA SOCIAL EM FRONTEIRA
}

Presence of international migrants in education and social assistance in border

Presencia de migrantes internacionales en educación y asistencia social en frontera

\author{
Marco Aurélio Machado de Oliveira* \\ Renata Miceno Papa de Almeida** \\ Mabel Marinho Sahib Aguilar***
}

\begin{abstract}
*Universidade Federal de Mato Grosso do Sul - marco.oliveira@ufms.br **Secretaria Municipal de Assistência Social de Corumbá, MS - renatapapa8@gmail.com **\$Secretaria Municipal de Educação de Corumbá, MS - mabel.aguilar@corumba.ms.gov.br
\end{abstract}

Recebido em 24/01/2020. Aceito para publicação em 17/03/2020

Versão online publicada em 05/05/2020 (http://seer.ufrgs.br/paraonde)

\section{Resumo:}

Este artigo tem como objetivo demonstrar a presença de migrantes internacionais na rede municipal de educação e assistência social em Corumbá, MS, Brasil. Nossos estudos foram balizados por conceitos de fronteira que dessem conta de entender como as esferas administrativas em questão têm que lidar com esse público e suas especificidades. Para tanto, as etapas metodológicas adotadas foram: ampla revisão bibliográfica, coleta e sistematização de dados nos órgãos investigados e realização de abordagens junto aos seus funcionários. Os resultados foram: demonstração de variadas nacionalidades e conflitos de opiniões a respeito da presença desses grupos sociais.

Palavras-chave: Fronteira; Migrações Internacionais; Educação; Assistência Social; Política.

\begin{abstract}
:
This article aims to demonstrate the presence of international migrants in municipal school system and social assistance in Corumbá, MS, Brazil. Our studies were marked by boundary concepts that could understand how the administrative spheres in question have to deal with this public and its specificities. To this end, the methodological steps adopted were: extensive bibliographic review, data collection and systematization in the investigated bodies and realization of approaches with their employees. The results were: demonstration of various nationalities and conflicts of opinion about the presence of these social groups.
\end{abstract}

Key words: Border; International migrations; Education; Social assistance; Politics.

\section{Resumen:}

Este artículo tiene como objetivo demostrar la presencia de migrantes internacionales en red municipal de educación y asistencia social en Corumbá, MS, Brasil. Nuestros estudios estuvieron marcados por conceptos de límites que podían comprender cómo las esferas administrativas en cuestión tienen que lidiar con este público y sus especificidades. Para este fin, los pasos 
metodológicos adoptados fueron: revisión bibliográfica extensa, recolección de datos y sistematización en los organismos investigados y realización de enfoques con sus empleados. Los resultados fueron: demostración de diversas nacionalidades y conflictos de opinión sobre la presencia de estos grupos sociales.

Palabras Clave: Frontera; Migraciones internacionales; Educación; Asistencia social; Política.

\section{Introdução}

Este artigo é fruto de pesquisa em andamento no âmbito do Mestrado em estudos Fronteiriços da Universidade Federal de Mato Grosso do Sul, Brasil. E tem como objetivo demonstrar a presença de migrantes internacionais na oferta de políticas públicas na educação e assistência social em Corumbá, MS, Brasil. Por estar situada na fronteira Brasil-Bolívia, localizada no centro do continente sul-americano, esta cidade possui histórica presença desses grupos sociais. Analisamos suas presenças na atualidade em dois equipamentos públicos: o Albergue e a Rede Municipal de Ensino (REME), onde se tornam mais visíveis e quantificáveis.

Nossos estudos foram balizados por conceitos de fronteira que dessem conta de entender como as esferas administrativas em questão têm que lidar com esse público e suas especificidades. Neste aspecto, consideramos importante salientar a necessidade realizar a marcação de nossas observações a partir das esferas políticas localizadas na fronteira, buscando, assim, nos distanciar de enredos nos quais ela é analisada como um espaço deliberativo de um fluxo em direção às metrópoles. Para tanto, uma das etapas metodológicas mais relevantes foi uma abrangente revisão bibliográfica que apontasse para as possibilidades de compreensão de como o fenômeno migratório internacional é absorvido, principalmente, pelas esferas da baixa política. Consideramos a revisão bibliográfica não como um apanhado de referenciais, mas, sim, como uma releitura minuciosa de elementos constitutivos de conceitos e de parâmetros a respeito de fronteira, migração internacional e política.

Outro procedimento metodológico que adotamos foi a coleta de dados junto aos órgãos investigados e suas sistematizações, organizando por períodos de ocorrência de presença dos migrantes internacionais, bem como suas nacionalidades. Tais dados foram obtidos junto aos sistemas de gestão internos a cada secretaria envolvida, o que deu confiabilidade à pesquisa, uma vez que são gerados a partir de apresentações documentais por parte desse público-alvo. Realizamos abordagens, que consistiram na captura de percepções, ideias e sentimentos, junto a servidores de ambas as esferas administrativas, tanto os que atuam diretamente com esse público quanto os que trabalham em níveis superiores da gestão. O procedimento para isso consistiu em: conversas presenciais e informais; e, diálogos através de ferramenta virtual, em específico o Whatsapp. Com isso apreendemos as formas como eles percebem a presença de migrantes internacionais, da mesma forma como buscam solucionar impasses administrativos.

ParaOnde!?, Porto Alegre, v.13, n.2, p.61-74, 2020.http://seer.ufrgs.br/paraonde Edição Especial - VII Seminário Internacional de Estudos Fronteriços 


\section{Corumbá: fronteira e migração internacional}

Corumbá é uma cidade que está localizada na fronteira do Brasil com a Bolívia, possuindo em torno de 110 mil habitantes. Porém, acrescentando as populações das vizinhas Ladário, no Brasil, e Puerto Quijarro e Puerto Suarez, na Bolívia, a população chega a algo em torno de 170 mil habitantes, conforme estimativas do Circuito Imigrante (Circuito) e do Laboratório de Estudos Fronteiriços (LEF), da Universidade Federal de Mato Grosso do Sul. A história da presença de imigrantes em Corumbá, em especial após a Guerra com o Paraguai, pode ser entendida a partir de uma centralidade espacial construída por diversos elementos, como, por exemplo, as atividades mercantis abastecedoras do antigo Mato Grosso até meados dos anos 1920 (OLIVEIRA; ESSELIN, 2005). Isso foi capaz de lhe dar dinamismo e se tornar polo atrativo de correntes migratórias internacionais naquele período (OLIVEIRA; JUNQUEIRA, 2016). Para lá migraram mais de 20 nacionalidades de 3 continentes (IDEM), em uma cidade com pouco mais de 10 mil habitantes e 9 representações consulares. Desta forma, essa fronteira que envolve Corumbá pode ser compreendida como pertencente a um importante espaço nos fluxos migratórios no centro continente sul-americano até a atualidade.

No que diz respeito aos fluxos migratórios de bolivianos em direção àquela cidade, em nosso entendimento, foi acentuado a partir da Guerra do Chaco (1932-1935) e potencializado no período de construção da ferrovia que liga Corumbá a Santa Cruz de la Sierra (1939-1954), quando diversos trabalhadores foram recrutados para esse empreendimento. Eram, em sua maioria, advindos da região da Chiquitania, no Departamento de Santa Cruz, envolvendo as cidades de Roboré e San José de Chiquitos (SILVA, 2009). Esse adensamento populacional promoveu variados níveis de interações entre suas populações, fazendo desta fronteira palco de conectividades bastante intensas. Neste sentido, Silva (2009) constata que a construção da ferrovia redefiniu os parâmetros sociais daquela fronteira. Salienta que aqueles imigrantes teriam sido empregados em ofícios na construção daquela ferrovia ou, ainda, nas condições subalternas na dinâmica socioeconômica, como: domésticas, serventes, etc. Para aquele autor, os bolivianos passaram a exercer fortes e amplas influências, indo desde as questões relativas ao emprego de forças laborais até hábitos alimentares.

Ainda não foi possível comprovar o período em que os bolivianos oriundos do Altiplano começaram a migrar de maneira mais intensa em direção à fronteira em estudo. Para alguns pesquisadores isso teria ocorrido após a inserção daquele país - de maneira semelhante, porém, menos vigorosa do que no Paraguai (ALBUQUERQUE, 2010, p. 67) - nas redes internacionais de comércio de produtos oriundos da Ásia, especialmente da China e do Japão. Esse processo teria seu início nos princípios dos anos 1980 (LOIO; MARINI; OLIVEIRA, 2017, p. 227).

Constatamos que naquela fronteira, na atualidade, ocorre a tripla tipificação da imigração: os permanentes, que emigraram para um dos países vizinhos, e lá se estabeleceram; os de passagem, que fazem uso da fronteira como uma instância deliberativa para seu ingresso em um dos territórios

ParaOnde!?, Porto Alegre, v.13, n.2, p.61-74, 2020.http://seer.ufrgs.br/paraonde Edição Especial - VII Seminário Internacional de Estudos Fronteriços 
nacionais; e os pendulares, que desenvolvem atividades empreendedoras, laborais ou estudantis no país vizinho, retornando para seu país de origem rotineiramente (CORRÊA, 2016). Neste aspecto, Corumbá exerce centralidades, uma vez que os movimentos pendulares estão estabelecidos naquela cidade em direção a todas as outras e em via dupla (OLIVEIRA; MARINI; LOIO, 2018). E, no que diz respeito a este artigo, notamos que os bolivianos prevalecem entre os pendulares naquela fronteira, embora façam parte deste processo também brasileiros, peruanos, colombianos, nigerianos, chilenos e argentinos que residem na Bolívia, além dos brasileiros, bolivianos e paraguaios, que vivem do lado brasileiro.

Com esse histórico migratório e com este conjunto de cidades que compõe a fronteira em estudo, Corumbá exerceu e exerce diversas centralidades, podendo ser verificadas no campo laboral ou na saúde, por exemplo. Isso pôde ser constatado em levantamento que realizamos no acervo do Fórum da Comarca dessa cidade, onde encontramos diversos registros de processos trabalhistas e obituários envolvendo pessoas que não eram nascidas em território brasileiro, entre os anos 1930 e 1970. Isso também é verificável na atualidade como, por exemplo, no caso dos estudantes brasileiros que vivem na Bolívia, mas diariamente cruzam o limite entre ambos os países para suas atividades estudantis em Corumbá (GOLIN, 2017). Ou, os feirantes que pendulam cotidianamente para vender seus produtos nas feiras livres nesta cidade (LOIO, 2018). Há, também, os que fazem uso do sistema de saúde para diversos tipos de demandas.

No Censo Demográfico de 2010, o Instituto Brasileiro de Geografia e Estatística (IBGE) contabilizou 1.282 estrangeiros vivendo em Corumbá, entre naturalizados (546) e não naturalizados (736). O LEF e o Circuito têm trabalhado com estimativas maiores do que esses números, uma vez que a presença boliviana, por ser a majoritária, e de outras nacionalidades residindo na cidade pode ser mais expressiva do que os números oficiais. Nos levantamentos que estamos realizando junto a diversos órgãos, conseguimos contabilizar mais de 20 nacionalidades habitando, na atualidade, aquela cidade.

Além da presença marcante dos pendulares, é possível constatar o fluxo intenso e regular de migrantes internacionais de passagem. Os mais volumosos, historicamente, são os bolivianos (SILVA, 2006), com rotas consolidadas em direção, principalmente, a São Paulo. Contudo, outras nacionalidades também fazem uso desta fronteira para ingressar em território brasileiro, como nigerianos, ganenses, camaronenses, por exemplo. Embora em número muito menor que os bolivianos, esses grupos de migrantes internacionais são constantes naquela fronteira. Estamos tratando de solicitantes de refúgio e imigrantes que passam por aquele espaço em busca de melhores oportunidades para suas vidas.

Desde fevereiro de 2018 Corumbá tem assistido um aumento expressivo da presença de haitianos na modalidade migratória de passagem pela fronteira. São, em sua imensa maioria, oriundos do Chile, uma vez que a partir do início da segunda gestão do Presidente Sebastián Piñera em 2018, o governo

ParaOnde!?, Porto Alegre, v.13, n.2, p.61-74, 2020.http://seer.ufrgs.br/paraonde Edição Especial - VII Seminário Internacional de Estudos Fronteriços 
chileno adotou um conjunto de medidas políticas migratórias nas quais determinou que, a partir de agosto daquele ano, aqueles que não estivessem regularizados no país deveriam deixá-lo. Essas medidas atingiram, principalmente, os haitianos, o que, para alguns estudiosos, era o objetivo a ser alcançado (MALDONADO, 2018), e os levou a um novo e intenso fluxo migratório. O destino prioritário para muitos deles foi o Brasil.

Nos meses seguintes ocorreu aumento significativo do fluxo de haitianos na cidade, ao mesmo tempo em que a Polícia Federal sinalizava não ter recursos humanos de atender com a mesma rapidez com que eles chegavam. Adotou-se uma medida de atender 15 haitianos por dia, na sede da Delegacia, durante seu funcionamento de segunda-feira a sexta-feira, o que não deu 0 resultado positivo. O resultado disso foi um gargalo administrativo, levando a esperas muito longas desses migrantes, que, conforme nos relataram, tinham que aguardar os agendamentos, feitos pela internet, com prazos de até dois meses.

O LEF e o Circuito trabalharam com a estimativa de 200 haitianos retidos na cidade a espera de atendimento nos meses de abril e maio de 2018, enquanto que em junho esse número chegou a 400. A Casa de Passagem José Lins (Albergue), o único espaço público com missão de dar acolhimento como leitos e alimentação, não conseguia abrigar tal volume, uma vez que sua capacidade é bastante limitada. A situação se tornou crítica, especialmente, pela morosidade da municipalidade em dar respostas no tocante ao acolhimento. Parcela da sociedade local, espontaneamente, deu sua parcela de contribuição para mitigar os efeitos daquele represamento.

Durante os meses de maio e junho os contornos da presença haitiana se tornaram mais dramáticos, levando alguns hotéis, notadamente os mais humildes, e algumas famílias a abrirem suas portas para dar a acolhida que as esferas administrativas não conseguiam dar. Diversos foram os haitianos que tiveram que dormir no chão do terminal rodoviário e da estação ferroviária. $O$ LEF e o Circuito contabilizaram, durante aqueles meses, 9 residências, 1 ONG e 3 hotéis dando abrigo a, aproximadamente, 500 haitianos, sendo que as vagas eram preferenciais para famílias e mulheres grávidas e/ou com crianças.

Essa realidade impacta na administração pública municipal de diversas formas, produzindo efeitos distintos entre os agentes que os atendem. Neste sentido, cabe compreender a fronteira como palco de ações políticas entre os estados e podem ser consideradas como processos e instituições importantes nas análises que são feitas a partir e sobre elas (ANDERSON, 1997). Trata-se de uma relevante consideração a respeito das fronteiras, uma vez que, por conta de inclinações políticas, tende-se, incluindo no sentido acadêmico, a separá-la dos contextos nacionais que a compõem. As esferas políticas, e não falamos aqui apenas das administrativas, mas, sobretudo das que formam e dão sentido ao estado, são claras em suas definições e atribuições. Para Anderson (1994) tais esferas são apenas duas: a alta e a baixa política. Esse autor afirma que a alta política é composta pelas ações mais nobres da administração, ligadas à diplomacia e à defesa, ou seja, definindo as pautas e os assuntos internos e externos de uma nação. Enquanto a baixa política é

ParaOnde!?, Porto Alegre, v.13, n.2, p.61-74, 2020.http://seer.ufrgs.br/paraonde Edição Especial - VII Seminário Internacional de Estudos Fronteriços 
aquela que trata dos assuntos cotidianos das coisas públicas, ligada, portanto, à cobrança de impostos, policiamentos, distribuições espaciais da saúde e da educação, etc. (ANDERSON, 1994).

Como salienta Jacobson (1997), a migração internacional, invariavelmente, implica em riscos de declínios da cidadania, em seu sentido mais amplo. Essa constatação torna a leitura sobre a presença de migrantes internacionais em fronteira mais cautelosa. Isso porque as fronteira possui como um de seus elementos mais contundentes a ausência de políticas públicas que tenham atendimento e amplitude frente suas especificidades.

Iremos abordar alguns aspectos dessas presenças, especialmente, no que tange à Educação e à Assistência Social, como forma de ilustrar como os imigrantes são atendidos mediantes a existência de políticas públicas, incluindo as formas como agentes públicos reagem à presença deles. Paasi e Prokkola (2008) consideram serviços públicos ligados à educação e assistência social como esferas administrativas onde os migrantes internacionais mais têm possibilidades de receber acolhida humanitária e condições de obter encaminhamento de acesso digno a serviços essenciais. Desta forma, esses espaços foram selecionados, primeiro, por fazerem parte da rotina profissional dos autores e, segundo, por encontrarmos diversas contradições potencializadas pelas condições de fronteira vividas naquela cidade.

\section{Presença de imigrantes nos contextos educacionais}

A Rede Municipal de Ensino (REME) em Corumbá possui 40 unidades escolares e 17 extensões distribuídas na área urbana e rural do município, que atendem alunos da educação infantil (creche e pré-escola), ensino fundamental I ( $1^{\circ}$ ao $5^{\circ}$ ano), ensino fundamental II (6ำ ao $9^{\circ}$ ano) e a EJA - Educação de jovens e adultos. A REME atende migrantes internacionais nos tipos pendulares e permanentes (GOLIN, 2017), e dividem as salas de aula alunos brasileiros e estrangeiros, com hábitos e culturas diferentes. Neste aspecto, consideramos importante observar que "[...] fronteira e cultura carregam os traços das relações econômicas, políticas, éticas, morais, religiosas, particulares de cada ambiente construído e, sobretudo de relações de poder." E isso, em diversos momentos é manifestado. A REME ainda não possui dados básicos sobre o fluxo escolar na fronteira em estudo, portanto são sujeitos excluídos de políticas educacionais em Corumbá, como, por exemplo, na oferta de linhas de ônibus de transporte escolar que os conduza até o limite entre os países.

Segundo Golin (2017), quando se trata da educação fronteiriça, um detalhe importante é a diferenças de idiomas entre os países. O português é a língua mãe para os brasileiros e, predominantemente é ensinado nas escolas o inglês, como língua estrangeira moderna. Essa realidade desconsidera o idioma espanhol, que é a principal língua oficial dos países fronteiriços que se avizinham ao Brasil, e essa desconsideração pode deflagrar distanciamentos formais das instituições educativas, sobretudo se considerarmos, em termos fronteiriços, a negligência dessa língua estrangeira no Brasil. Ou seja, o fato de não haver o ensino regular da língua espanhola é, em nosso entendimento, um

ParaOnde!?, Porto Alegre, v.13, n.2, p.61-74, 2020.http://seer.ufrgs.br/paraonde Edição Especial - VII Seminário Internacional de Estudos Fronteriços 
obstáculo considerável para possibilidades de integração entre instituições e para o processo de ensino-aprendizagem, uma vez que a imensa maioria dos alunos estrangeiros é oriunda de países de língua hispânica.

O município de Corumbá não possui legislação específica para educação que considere sua condição de cidade-gêmea fronteiriça, tampouco possui regulamentação para o ensino do idioma espanhol nas séries iniciais, no caso, o Ensino Fundamental I. Contudo, a partir do ano 2012, o município em atendimento ao disposto no $\S 4^{\circ}$ do art. $2^{\circ}$ da Lei N 11.738, de 16 de julho de 2008 (Lei do Piso Nacional do Magistério) e nos incisos I e II do art. 32 da Lei Complementar Municipal № 150, de 4 de abril de 2012, regulamentada pelo decreto Municipal № 1.060, de 21 de junho de 2012, regulamenta as horasatividades dos profissionais de educação, previstas no Plano de Carreira e Remuneração do Magistério Municipal, para tanto houve uma alteração na base diversificada da matriz curricular que inseriu o ensino da língua estrangeira no Ensino Fundamental I (séries inicias). Desde então as escolas que apresentavam o maior número de alunos estrangeiros passaram a ofertar o espanhol como língua estrangeira na base diversificada, devidamente aprovada pelo Conselho Municipal de Educação daquele município.

Tabela 1 - Alunos estrangeiros na Rede Municipal de ensino em Corumbá, MS (2013-2018)

\begin{tabular}{lllllll}
\hline $\begin{array}{l}\text { País de } \\
\text { origem }\end{array}$ & 2013 & 2014 & 2015 & 2016 & 2017 & 2018 \\
\hline $\begin{array}{l}\text { Arábia } \\
\text { Saudita }\end{array}$ & 1 & 1 & 2 & 2 & - & - \\
Bolívia & 25 & 28 & 29 & 41 & 52 & 61 \\
Abssínia & 1 & 1 & 1 & 1 & 1 & 2 \\
Estados & 2 & - & - & 1 & - & - \\
Unidos da & & & & & & \\
América & & & & & & \\
Japão & 5 & 4 & 6 & 8 & 3 & 2 \\
Jordânia & 2 & 2 & 3 & 2 & - & 1 \\
Paraguai & 1 & - & 3 & 6 & - & 2 \\
Peru & 1 & - & - & - & - & - \\
Espanha & 3 & 1 & 1 & 2 & - & 2 \\
Palestina & - & - & - & 1 & - & - \\
Cuba & - & - & - & - & 2 & - \\
Colômbia & - & - & - & - & - & 1 \\
Venezuela & - & - & - & - & - & 2 \\
\hline
\end{tabular}

Fonte: Secretaria Municipal de Educação, Corumbá, MS.

Realizamos abordagens junto a diretores, coordenadores pedagógicos, professores e motorista de transporte escolar de unidades localizadas na zona urbana e rural do município, incluindo assentamento próximo à linha de fronteira. Percebemos nas falas que afirmam não existir preconceito com relação aos alunos estrangeiros nas escolas. Para os diretores, esses alunos,

ParaOnde!?, Porto Alegre, v.13, n.2, p.61-74, 2020.http://seer.ufrgs.br/paraonde Edição Especial - VII Seminário Internacional de Estudos Fronteriços 
cuja maioria é de bolivianos, não sofrem bullying por parte dos brasileiros. Em suas opiniões, esses alunos se discriminam ao não se apresentarem como estrangeiros, mas sim como brasileiros. Afirmam que eles não apresentam dificuldades com a língua, em especial os que lá estudam desde a creche e pré-escola, sendo que percebem dificuldades com aqueles que chegam para cursar o Fundamental e não conhecem o idioma português, ocasionando baixo rendimento escolar.

Ainda na opinião dos diretores, os pais "[...] são sempre presentes e interessados na vida escolar do aluno e dispostos a participar de atividades que possam agregar valor para a escola". Observam que nas escolas onde é ofertado o espanhol como língua estrangeira moderna a interação e troca de vivências é ainda maior. No caso das merendas oferecidas nas escolas de educação integral, onde é servida em três refeições, o cardápio é bem aceito pelos estrangeiros.

A percepção de uma coordenadora pedagógica de educação infantil é de que os estrangeiros "[...] interagem muito bem com os brasileiros, não existindo preconceito, talvez por serem crianças, e também não tem dificuldade com o idioma e com a aprendizagem". Na escola em que ela atua é ofertado o espanhol como língua estrangeira, o que, em sua opinião "[...] facilita muito a comunicação, pois são inteligentes e assimilam com facilidade a língua portuguesa". Os pais são presentes e muito participativos, sempre dispostos a colaborar com a escola, com material para os filhos, sendo "[...] muito mais interessados que muitos brasileiros".

Para uma professora regente do $1^{\circ}$ ano do Ensino Fundamental I, que tem matriculados e frequentes em sua turma 03 alunos estrangeiros, sendo 02 bolivianos e 01 aluna colombiana, e que "[...] todos moram na fronteira do lado boliviano e interagem com as outras crianças". Essa professora considera essas crianças como participativas, interessadas, que "[...] aprendem com facilidade e estão sendo alfabetizados (lendo e escrevendo), ótimo rendimento, igual ao dos brasileiros". Em sua opinião, a maior dificuldade está na pronúncia de algumas letras do alfabeto. Para a professora, um ponto positivo para o desempenho dos alunos é o fato dela ser filha de boliviana, uma vez que domina o idioma espanhol, facilitando o processo ensino-aprendizagem. Afirma que esses alunos são frequentes às aulas, inclusive em atividades extraclasse, sábados letivos, e que os pais são presentes e participativos, dispostos a ajudar a escola e nas tarefas diárias dos filhos.

Para o motorista que trabalha no transporte escolar e atua na linha que liga uma escola localizada em um assentamento rural até o limite Brasil-Bolívia, 95\% da crianças transportadas por ele moram "[...] na fronteira do lado boliviano, são filhos de pais bolivianos, porém nascidos no Brasil". Afirma que interage no ônibus com crianças sem qualquer distinção, conversam em português e algumas vezes entre eles em espanhol.

ParaOnde!?, Porto Alegre, v.13, n.2, p.61-74, 2020.http://seer.ufrgs.br/paraonde Edição Especial - VII Seminário Internacional de Estudos Fronteriços 


\section{Presença de imigrantes na Casa de Passagem José Lins}

Em importante e influente texto, Michel Foucher (1991) tipifica a fronteira em aberta, semiaberta e fechada. Historicamente, a fronteira em estudo é caracterizada como aberta, seja pela força dos acordos com a Bolívia, seja pela vivência com os vizinhos, que, em muitos aspectos, sobrepõe-se às legislações e acordos internacionais. Assim, ao entrar no Brasil, o migrante internacional, protocolarmente, deve iniciar sua regularização documental no Posto Terrestre de Controle de Migratório (PTCM) da Polícia Federal, localizado na linha limítrofe entre os países, em um complexo fiscalizador conhecido Posto Esdras. Por se tratar de uma fronteira aberta, há casos de migrantes internacionais com vistos negados e/ou impedidos de adentrarem regularmente no Brasil, ou que não fizeram os procedimentos administrativos naquele Posto, que acessam o país de forma irregular. Esses também chegam aos serviços públicos naquela cidade.

O imigrante regularizado documentalmente recebe orientação, principalmente da Pastoral da Mobilidade Humana $(\mathrm{PMH})$, para que seja encaminhado para os serviços assistenciais municipais. Dentre esses serviços, destacamos quanto a esse público: Albergue ou o Centro de Referência Especializado para Pessoa em Situação de Rua (Centro POP), equipamentos públicos vinculados à Secretaria Municipal de Assistência Social. No caso deste artigo, o Albergue possui maior destaque por ser um espaço em que o migrante internacional dorme, faz refeições, toma banho e interage, ou não, com funcionários e outros usuários da Casa. Portanto, é um local que possui muitas complexidades, uma vez que sua missão não se restringe ao acolhimento a esse grupo social, mas, também, a pessoas em situação de rua, idosos abandonados pela família, mulheres em medidas de proteção contra a violência, dentre outros.

Criado em 1974, por Dora Otto Lins, e municipalizado em 1996, o Albergue está localizado na rua Edu Rocha, no Bairro Aeroporto, equidistante em cerca de 4 quilômetros do centro da cidade, onde se localiza a Delegacia da Polícia Federal e o limite Brasil-Bolívia, onde se situa o PTCM. Citamos esses pontos de referência por serem os locais onde os migrantes refugiados devem se dirigir para regularizarem documentalmente no Brasil. Dista cerca de 400 metros da $\mathrm{PMH}$, local onde recebem orientações e encaminhamentos.

Atualmente, o Albergue conta com uma estrutura que inclui alojamento dividido entre homens e mulheres, com capacidade de 11 leitos para cada um deles. Em seu espaço ainda consta cozinha, copa, banheiros com chuveiros e sanitários, refeitório, que serve, também, como área de convivência almoxarifado, dormitório de educador social e espaço externo. Possui uma sala administrativa e outra para apoio psicológico. Em seu quadro de pessoal atuam 05 educadores sociais (ensino médio/superior), 02 auxiliares de serviços operacionais, 02 cozinheiras, 01 psicóloga e a coordenadora. No período noturno existe 01 Guarda Municipal.

Trazemos neste artigo dados relativos à presença migrante internacional no Albergue no período de 2016 a 2018. Isso se deve ao fato de até 2015 os dados estarem demasiados incompletos para análise. Podemos

ParaOnde!?, Porto Alegre, v.13, n.2, p.61-74, 2020.http://seer.ufrgs.br/paraonde Edição Especial - VII Seminário Internacional de Estudos Fronteriços 
observar na tabela 2, que os migrantes são se origens variadas, tendo passado por aquele espaço 20 nacionalidades em 2016, 15 em 2017 e 10 em 2018. Um dos resultados mais impactantes dessa variedade de nacionalidades é que eles correspondiam em 2016 a 11 idiomas distintos, além do português, em 2017 eram 07 e em 2018 foram 05 idiomas.

Tabela 2 - Imigrantes que fizeram uso dos serviços da Casa de Passagem José Lins - "Albergue da Fraternidade".

\begin{tabular}{|c|c|c|c|}
\hline Nacionalidade & 2016 & 2017 & 2018 \\
\hline África & - & 5 & - \\
\hline Alemanha & 2 & - & - \\
\hline Argentina & 43 & 25 & 8 \\
\hline Bolívia & 32 & 13 & 12 \\
\hline Camarões & - & 2 & 1 \\
\hline Chile & 27 & 25 & 1 \\
\hline Colômbia & 23 & 51 & 22 \\
\hline Equador & 1 & 4 & - \\
\hline Espanha & 7 & - & 1 \\
\hline $\begin{array}{l}\text { Estados Unidos } \\
\text { da América }\end{array}$ & 2 & - & - \\
\hline França & 1 & 1 & - \\
\hline Gambia & - & 2 & - \\
\hline Gana & 1 & - & - \\
\hline Guiné & 3 & - & - \\
\hline Haiti & 2 & 5 & 116 \\
\hline Hungria & 10 & - & - \\
\hline Índia & - & 1 & - \\
\hline Itália & 5 & - & - \\
\hline Oceania & - & 1 & - \\
\hline Paraguai & 2 & - & - \\
\hline Peru & 18 & 11 & 2 \\
\hline Polônia & - & - & 1 \\
\hline República & 8 & - & - \\
\hline Dominicana & & & \\
\hline Senegal & 3 & - & - \\
\hline Togo & - & - & 6 \\
\hline Ucrânia & 1 & - & - \\
\hline Uruguai & 5 & 2 & - \\
\hline Venezuela & - & 6 & - \\
\hline Total & 197 & 154 & 170 \\
\hline
\end{tabular}

Fonte; Secretaria Municipal de Assistência Social, Corumbá, MS.

Essa variedade idiomática impôs dificuldades de comunicação aos servidores da Casa, que se queixam de falta de qualificações que os capacitem para melhores comunicações. Todavia, em abordagens junto a gestores da Assistência Social, um problema foi levantado: como capacitá-los para tantos idiomas? Ademais, em quantos seriam necessários capacitá-los, uma vez que 
migrantes oriundos de todos os continentes passam por ali? De fato, as dificuldades enormes foram enfrentadas com criatividade e observação nos meios que os grupos de migrantes lançavam para se comunicar. Foi desta forma que, além da mímica, os servidores passaram a notar que os haitianos estavam fazendo uso de aplicativos no celular para poderem se comunicar com os que não eram de suas nacionalidades. Foi, então, que eles conheceram esta finalidade da ferramenta Google Tradutor, de uso gratuito e fácil acesso pela internet.

Realizamos abordagens junto aos servidores da SMAS que atuam direta ou indiretamente com esses grupos sociais e pudemos capturar diversas falas que demonstram as formas como eles são percebidos. Os funcionários que possuem cargos em níveis mais elevados, por exemplo, demonstram a preocupação gerencial enfatizando a necessidade dos segmentos administrativos da esfera federal ter olhares diferenciados para a questão, principalmente, quanto aos repasses financeiros. Outra preocupação está na necessidade de criar programação de formações e atualizações sistemáticas e permanentes para funcionários atuantes diretamente nos órgão de acolhimento e atendimento, com viés de assimilar as demandas específicas apresentadas na migração de passagem, por ser essa a realidade local.

Quanto mais nos aproximamos dos que atuam diretamente mais as tensões afloram. Uma técnica da SMAS, de nível médio na hierarquia, percebe ser o imigrante "um incômodo", pois existem as demandas locais, com problemáticas e complexidades diversas. $\mathrm{O}$ imigrante acolhido e/ou atendido nos órgão municipais locais "causam grande sobrecarga laboral, outras demandas além de serem estrangeiros, em outras palavras, não percebe coser cidadão detentor de direitos". Em outra abordagem, a educadora social que atua no Albergue afirmou que a maioria dos imigrantes acolhidos possui "a mesma 'historinha', foram roubados, teve seus documentos extraviados no caminho, não possuem recursos, são 'coitadinhos'". Reforça ser adepta do "modelo norte-americano ou europeu", que segundo ela "exige do estrangeiro além dos documentos obrigatórios, comprovação de recursos financeiros e apresentação de passagem de retorno". Disse ser aceitável que venham em busca de melhores condições, porém não "ao léu", devendo "comprovar emprego no Brasil". Pois, alegou "sobrar" para o país a resolução de atendimento de demandas que "não são nossas".

No tocante à Coordenação do Albergue, a visão é mais no sentido de proporcionar o acolhimento "pois todos atravessam situações difíceis, ocasionadas por longos e penosos trajetos, violações de direitos, extorsões e outros percalços, vulnerabilizando e fragilizando os que buscam o Albergue". Salientou que o órgão é "ponto de apoio, especialmente no quesito segurança, além de orientações, encaminhamentos e buscas céleres das necessidades básicas". Outra educadora social mencionou a necessidade de haver capacitações para que o atendimento tenha mais qualidade e segurança aos funcionários.

ParaOnde!?, Porto Alegre, v.13, n.2, p.61-74, 2020.http://seer.ufrgs.br/paraonde Edição Especial - VII Seminário Internacional de Estudos Fronteriços 


\section{Considerações Finais}

Com a realização desta pesquisa pudemos constatar as presenças de grupos de migrantes internacionais em segmentos da administração municipal em Corumbá, MS, mais precisamente, na educação e na assistência social. Pudemos constatar que quando esses órgãos possuem registros, isso torna mais provável dar visibilidades a eles visando garantir melhorias nos oferecimentos dessas políticas públicas.

A variedade de nacionalidades que pudemos constatar nesta pesquisa, comprova a dinâmica migratória internacional existente na fronteira em estudo, uma vez que Corumbá, por sua larga história relacionada aos fluxos migratórios internacionais é ponto de paragem e de passagem deles. As centralidades que esta cidade exerce são constatadas nos números de nacionalidades e de idiomas de pessoas que se utilizam daquelas políticas públicas.

A realização de qualificações que levem em conta as particularidades como língua, hábitos, costumes, dificuldades apresentadas no ensinoaprendizagem, evasão, estereótipos e discussões da realidade vivida nas escolas da fronteira em estudo ainda não foi tratada pela municipalidade como possibilidade de melhoria na qualidade de suas atividades. Da mesma forma, os servidores do Albergue carecem de qualificações que os permita oferecerem melhores serviços e com mais segurança, como reivindicaram. Os profissionais que atuam nesses ambientes necessitam de capacitações que melhorem suas percepções sobre o ambiente fronteiriço e as clientelas diversificadas que eles atendem.

As questões relacionadas á capacitação e qualificação de funcionários daqueles órgãos se tornam relevantes na medida em que analisamos suas percepções. Na assistência social, por exemplo, pudemos perceber que suas falas expressam preocupações administrativas e financeiras, bem como de aprimoramento do quadro de pessoal, ao passo que aqueles estão que têm seus cotidianos diretamente envolvidos com esse público, reproduz o senso comum dando a eles a responsabilidade pela sobrecarga no trabalho. $\mathrm{Na}$ educação, em outro exemplo, pudemos perceber que aqueles que ocupam cargos de direção e coordenação percebem a presença desses imigrantes a partir de formulários nos quais a avaliação do processo de ensinoaprendizagem se limita a resultados numéricos finais. Isso porque constroem seus entendimentos a partir da ideia de que os alunos que não são brasileiros possuem rendimento escolar equiparado aos nacionais a medida que foram aprovados. A realidade local precisa ser melhor percebida e trabalhada por eles.

Neste tocante, nossas pesquisas estão direcionadas para desenvolvimento de técnicas permanentes de qualificação dos profissionais que atuam em ambos os órgãos. Há a necessidade de promover revisões conceituais a respeito de fluxos migratórios e rendimento escolar junto aos servidores envolvidos. Da mesma forma, cremos que haja a premente necessidade de aprimorar a geração de dados, ampliando as informações e alimentando a gestão, em seus níveis superiores.

ParaOnde!?, Porto Alegre, v.13, n.2, p.61-74, 2020.http://seer.ufrgs.br/paraonde Edição Especial - VII Seminário Internacional de Estudos Fronteriços 


\section{Referências}

ALBUQUERQUE, L. J. A Dinâmica das Fronteiras: os brasiguaios entre o Brasil e o Paraguai. São Paulo: Annablume, 2010.

ANDERSON, M. Policing Across National Boundaries. London, Pinter, 1994.

"The Political Sciences and Frontiers". In: GANSTER, P.; SWEDLER, A.; SCOTT, J.; DIETER-EBERWEIN, W. (orgs.) Borders and Border Regions in Europe and North America. San Diego University Press, Institute for Regional Studies of the Californias, 1997, pp. 27-46.

CORRÊA, J. M. O Mestrado Profissional em Estudos Fronteiriços em perspectivas de inserção social: avaliações sobre a implantação do Circuito de Apoio ao Imigrante. Dissertação de Mestrado em Estudos Fronteiriços. UFMS/CPAN, 2016. 89 p.

COSTA, E. A. "Os bolivianos em Corumbá, MS: construção cultural multitemporal e multidimensional na fronteira". In: Cadernos de Estudos Culturais, Campo grande, MS, v. 4, n. 7, pp. 17-33, 2012.

FOUCHER, Michel. Fronts et Frontiéres: um tour du monde géopolitique. Paris, Fayard, 1991.

GOLIN, C. H. Educação Física na Fronteira Brasil-Bolívia: uma análise intercultural de uma escola pública no município de Corumbá-MS/Brasil. Tese de Doutorado. Universidade Católica de Brasília, PPG Educação Física, 2017, 239 pp.

JACOBSON, D. Rights Across Borders: Immigration and Decline of Citizenship. Baltimore, Maryland, USA, The Johns Hopkins University Press, 1997.

LOIO, J. A. M.; MARINI, J. F. M.; OLIVEIRA, M. A. O. "Imigrantes Bolivianos da Planície e do Altiplano em Região de Fronteira: Distinções Pregressas em Solidariedade Seletiva". In: In: Geopantanal, número especial, pp. 219-232, 2017.

MALDONADO, P. A. L. CRÓNICAS DE MIGRANTES HAITIANOS: Chile, ¿país de oportunidades? Santiago, Chile, Universidad de Chile, 2018.

OLIVEIRA, M. A. M.; JUNQUEIRA, N. M. Representações sociais de sírios e libaneses em Corumbá, MS: comércio, casamento e cemitério. In: Revista Transporte y Territorio. Buenos Aires, n. 15, pp. 388-403, 2016.

OLIVEIRA, T. C. M.; ESSELIN, P. M. "Localizando as Condições Pretéritas e as relações Correntes na Complexa Fronteira Brasil-Bolívia". In: Geosul, Florianópolis, v. 30, n. 60, pp. 125-163, 2015.

PAASI, A.; PROKKOLA, E-K. "Territorial Dynamics, Cross-border Work and Everyday Life in the Finnish-Swedish Border Area". In: Space and Polity, v. 12, n. 1, pp. 13-29, 2008.

SAYAD, Abdelmalek. A Imigração: ou os paradoxos da alteridade. São Paulo, Edusp, 1998.

ParaOnde!?, Porto Alegre, v.13, n.2, p.61-74, 2020.http://seer.ufrgs.br/paraonde Edição Especial - VII Seminário Internacional de Estudos Fronteriços 
SILVA, S. A. "Bolivianos em São Paulo: entre o sonho e a realidade". In: Estudos Avançados, São Paulo, v. 20, n. 57, pp. 157-170, 2006.

SILVA, G. J. A Presença Kamba-Chiquitano na Fronteira Brasil-Bolívia (1938-1987): identidade, migrações e práticas culturais. Tese de Doutorado. Programa de Pós-Graduação em História, Faculdade de História, Universidade Federal de Goiás. 2009. 